\title{
Chimney endovascular technique for acute retrograde type A dissection in a Jehovah's Witness
}

\footnotetext{
From the Divisions of a Cardiothoracic Surgery and ${ }^{\mathrm{b}}$ Vascular and Endovascular Therapy, Emory University School of Medicine, Atlanta, Ga.

Disclosures: Authors have nothing to disclose with regard to commercial support

Received for publication Nov 10, 2018; revisions received Dec 20, 2018; accepted for publication Dec 30, 2018; available ahead of print Feb 22, 2019.

Address for reprints: Bradley G. Leshnower, MD, Division of Cardiothoracic Surgery, Emory University School of Medicine, 1365 Clifton Rd, NE, Suite A 2213, Atlanta, GA 30322 (E-mail: bleshno@emory.edu).

J Thorac Cardiovasc Surg 2019; 157:e305-7

$0022-5223 / \$ 36.00$

Copyright (C) 2019 by The American Association for Thoracic Surgery

https://doi.org/10.1016/j.jtcvs.2018.12.100
}

Retrograde type A dissection complicates $16 \%$ of all acute type B aortic dissections. ${ }^{1}$ Although open repair remains first-line therapy, the need for hypothermic circulatory arrest can cause significant derangements in hemostasis necessitating blood transfusion. We report a case of a Jehovah's Witness presenting with retrograde type A dissection after acute type B aortic dissections who refused open repair. We describe a successful staged approach with complete cervical debranching followed by zone 0 TEVAR with innominate artery chimney graft.

\section{CLINICAL SUMMARY}

A 68-year-old Jehovah's Witness with poorly controlled hypertension presented to an outside hospital with uncomplicated acute type B aortic dissections (ATBAD). He was treated with optimal medical therapy; however, repeat imaging revealed retrograde propagation of the dissection flap into the ascending aorta with a patent false lumen (FL) (Figure 1). He was transferred to our institution and emergent open type A repair was recommended. However,

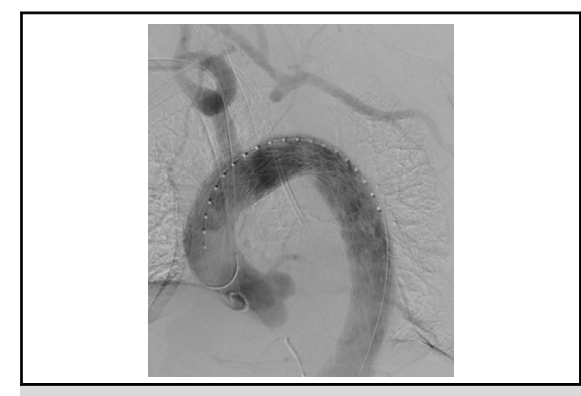

Completion aortogram demonstrating false lumen exclusion and patent chimney graft.

\section{Central Message}

Complete cervical debranching followed by zone 0 TEVAR and innominate artery chimney graft is a viable option to treat de novo acute retrograde type A dissection in a Jehovah's Witness.

See Commentary on page e309.

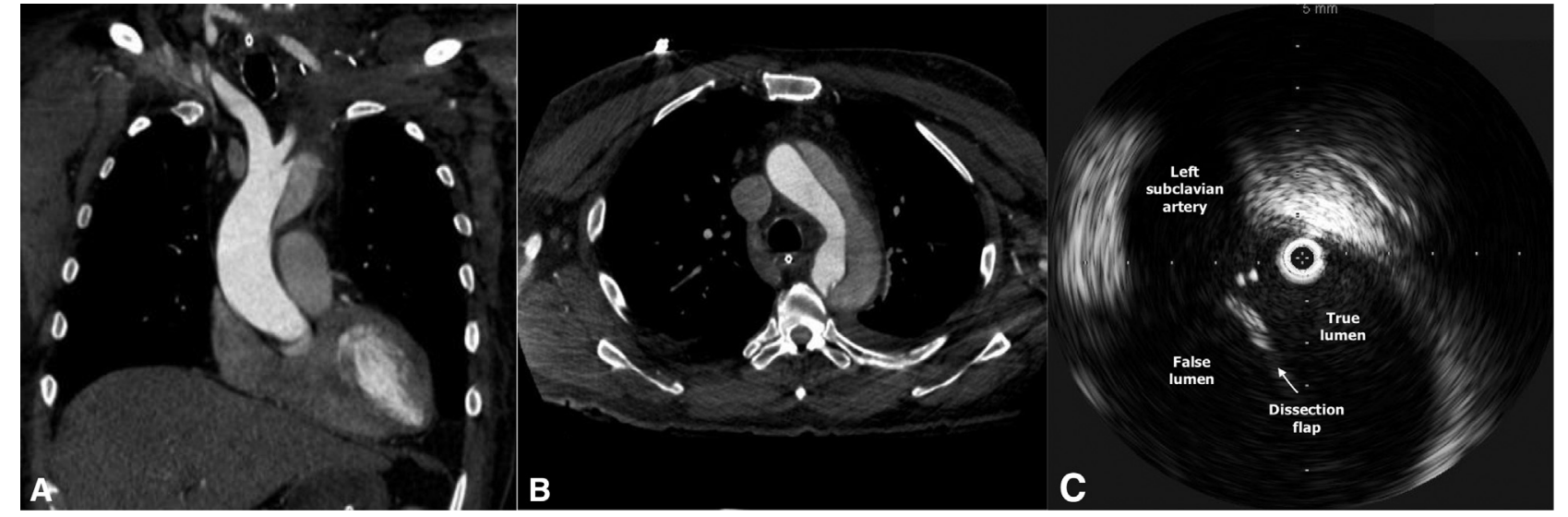

FIGURE 1. A, Coronal preoperative chest computed tomography scan. B, Axial preoperative chest computed tomography. Scans demonstrate retrograde propagation of dissection into the distal ascending aorta with patent false lumen. C, Intravascular ultrasound image depicting the primary intimal tear at the ostium of the left subclavian artery. 
artery access was achieved, and a $40 \times 40 \times 200 \mathrm{~mm}$ Conformable TAG Thoracic Endoprosthesis (CTAG) (Gore \& Associates, Flagstaff, Ariz) was advanced into the midascending aorta. After open right axillary artery exposure was obtained, a $16 \times 16 \times 12 \mathrm{~mm}$ Excluder (Gore \& Associates) iliac limb was advanced into the ascending aorta to deploy as a chimney graft. Rapid ventricular pacing (220 bpm) was initiated via a transfemoral pacer, reducing blood pressure to a nonpulsatile mean of $45 \mathrm{~mm} \mathrm{Hg}$, and the CTAG device was deployed. The Excluder endograft was deployed $2 \mathrm{~cm}$ proximal to the CTAG device. There were no changes in cerebral oximetry during deployment. Completion aortogram demonstrated elimination of antegrade FL perfusion and patency of all great vessels. The patient had an uneventful postoperative course. At 3-month follow-up, he was back to normal activities, and chest computed tomography scan demonstrated stable endograft position with complete FL obliteration (Figure 2).

\section{DISCUSSION}

Retrograde type A dissection (RTAD) is a known complication that can occur during medical treatment of ATBAD. Recent data from the International Registry of Acute Aortic Dissection found that RTAD is associated with better outcomes than classic type A dissection and may be treated as a separate entity. ${ }^{2}$ However, patients with RTAD with patent FL and dissection extending into zone 0 had higher mortality $(18.6 \%)$ than those with thrombosed FL and limited arch involvement $(8.6 \%)$. Among the former, mortality was highest in those treated medically. Therefore, emergent ascending aortic replacement remains the optimal

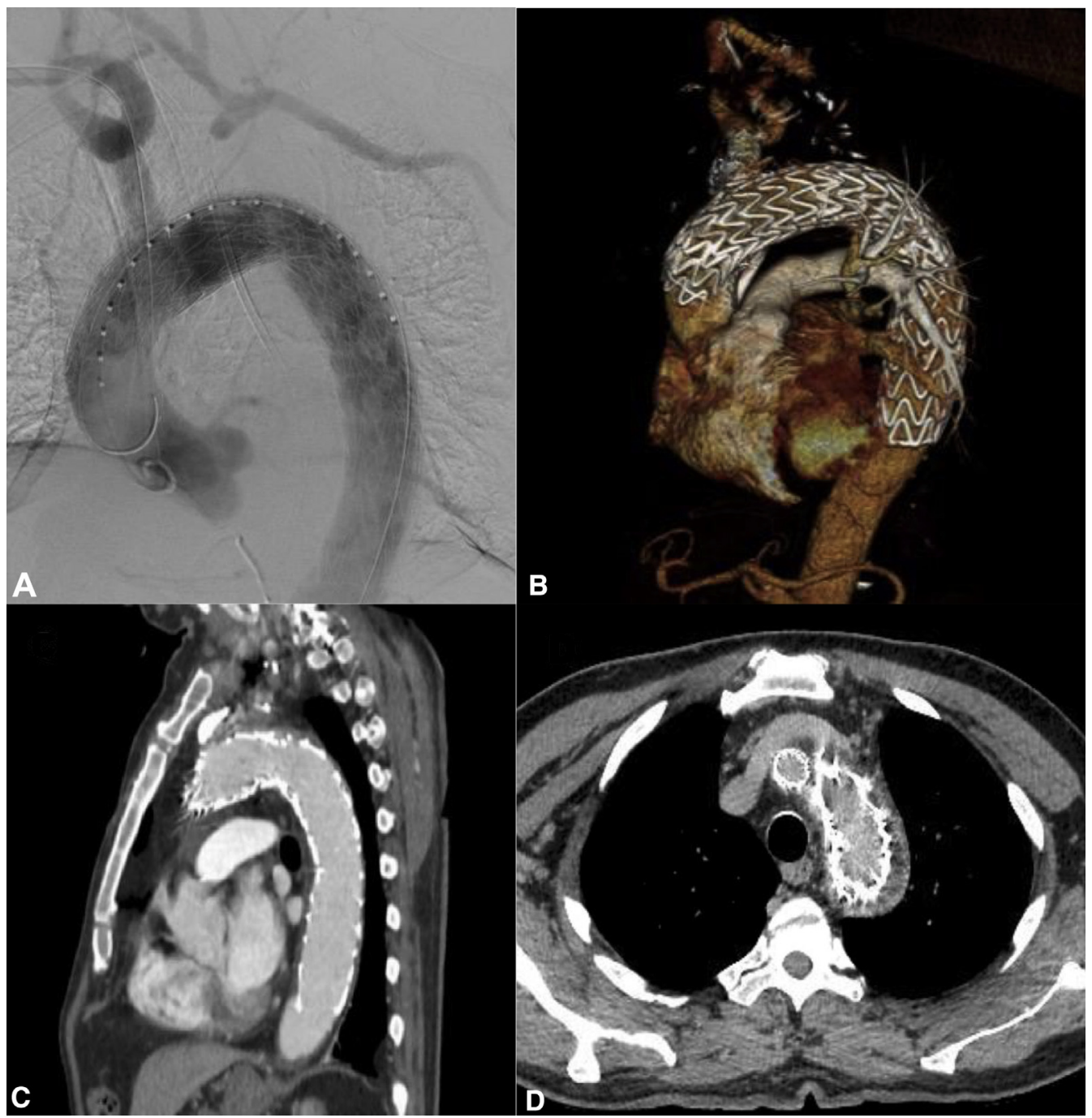

FIGURE 2. A, Completion aortogram demonstrating false lumen exclusion with filling of the innominate artery and cervical debranching bypasses. B, Graft positioning is delineated on TeraRecon image (TeraRecon Inc, Foster City, Calif). C, (Sagittal) Chest computed tomography scan at 3-month follow-up demonstrates complete false lumen obliteration with excellent distal aortic remodeling and no evidence of endoleak. D, (Axial) Chest computed tomography scan depicts the chimney graft within the ascending aorta. 
therapy. Surgical replacement of an acutely dissected proximal aorta can be performed with minimal blood transfusions; however, transfusions are frequently required. In patients refusing transfusions, their mortality risk with surgery may exceed that of medical management.

This patient presented with RTAD extending to zone 0 , patent FL, and retrograde flap extension into the ascending aorta. Given his religious beliefs and refusal of open aortic replacement, we proposed a hybrid solution with zone 0 TEVAR and cervical debranching. Currently, there are no commercially available branched endografts designed to treat aortic arch pathology. Therefore, we used a chimney graft technique to preserve innominate artery patency. An isolated case series by Zhang and colleagues ${ }^{3}$ described chimney graft use in RTAD. In a staged approach, they promoted FL thrombosis with coil embolization and Onyx glue (EV3, Plymouth, Minn.), creating a proximal landing zone, followed by chimney grafts with zones 1 to 2 TEVAR. ${ }^{3}$ Although favorable results were achieved, this technique was limited to FL diameter $\leq 20 \mathrm{~mm}$ and a median of 11 coils were required to achieve FL thrombosis. The use of chimney graft and zone 0 TEVAR to treat de novo RTAD has not been previously described.

The major limitation of the chimney technique is the gutter created between the graft and main endoprosthesis, which may contribute to an endoleak risk up to $15 \%$. Experience with chimney grafts in the abdominal aorta suggests that endoleak risk is decreased when the graft runs parallel to the endoprosthesis over a distance $>7 \mathrm{~cm} .{ }^{5}$ In our patient, proximal extension of graft coverage to zone
0 just above the sinotubular junction along the lesser curve of the aorta provided sufficient overlap with the chimney graft to avoid an endoleak, which remained the case on follow-up. This seal zone may be insufficient with a more extensive retrograde dissection propagating below the sinotubular junction or involving the greater curve, necessitating an alternative strategy.

\section{CONCLUSIONS}

Staged cervical debranching followed by zone 0 TEVAR with a chimney graft was successful in treating a Jehovah's Witness with de novo RTAD. Long-term data are still needed to assess the risks of stroke, migration, and endoleak of this technique before more widespread use can be advocated, but it may be a viable option for patients who cannot tolerate the risks of open surgery.

\section{References}

1. Nauta FJH, Tolenaar JL, Patel HJ, Appoo JJ, Tsi TT, Desai ND, et al. Impact of retrograde arch extension in acute type B aortic dissection on management and outcomes. Ann Thorac Surg. 2016;102:2036-43.

2. Nauta FJH, Kim JB, Patel HJ, Peterson MD, Eckstein HH, Khoynezhad A, et al. Early outcomes of acute retrograde dissection from the international registry of acute aortic dissection. Semin Thorac Cardiovasc Surg. 2016; 29:150-9.

3. Zhang R, Zhou J, Feng J, Zhao Z, Liu J, Li Z, et al. Inducing false lumen thrombosis for retrograde type A aortic dissection. J Thorac Cardiovasc Surg. 2017; 153: 57-65.

4. Bosiers MJ, Donas KP, Mangialardi N, Torsello G, Riambau V, Criado FJ, et al European multicenter registry for the performance of the chimney/snorkel technique in the treatment of aortic arch pathologic conditions. Ann Thorac Surg. 2016;101:2224-30.

5. Tolenaar JL, van Keulen JW, Trimarchi S, Muhs BE, Moll FL, van Herwaarden JA. The chimney graft, a systematic review. Ann Vasc Surg. 2012;26:1030-8. 